\title{
UM DOUTOR CONTRA DOUTOS LEIGOS: TEIXEIRA BRANDÃO E SUAS OPINIÕES QUANTO AO PODER DE DECISÃO SOBRE A CUSTÓDIA MÉDICA'
}

Richard Negreiros de Paula
Mestre pela Universidade Federal Fluminense e doutorando pela Casa de Oswaldo

Cruz - Fiocruz (COC/Fiocruz).

\begin{abstract}
Resumo
Partindo do contexto da disputa jurídica movida por Ernestina Ribeiro de Azevedo para se livrar do Hospício Nacional de Alienados, em 1897, o texto busca expor e analisar as opiniões de Teixeira Brandão, médico envolvido no caso e à época diretor do Hospício Nacional de Alienados, acerca da custódia exercida sobre os alienados mentais.
\end{abstract}

\section{Pallavras-chaves}

Custódia psiquiátrica $\bullet$ história da psiquiatria $\bullet$ história da medicina legal.

\section{Abstract}

Leaving of the context of the legal dispute moved by Ernestina Ribeiro de Azevedo to get rid itself of the Hospício Nacional de Alienados, in 1897, the text searchs to display and to analyze the opinions of Teixeira Brandão, involved doctor in the case and to the managing time of the Hospício Nacional de Alienados, concerning the safekeeping exerted on mentally illness.

\section{Keywords}

Psychiatric safekeeping $\bullet$ history of psychiatry $\bullet$ history of the forensis medicine.

\footnotetext{
${ }^{1}$ Este trabalho foi realizado com o apoio da bolsa de pesquisa concedida pela COC-Fiocruz - Rio de Janeiro - Brasil.
} 
Durante o processo de medicalização da loucura, que no Brasil teve início ainda na primeira metade do século XIX, os médicos alienistas, com o objetivo de embasar cientificamente seus argumentos, passaram a lançar mão de um instrumental teórico que tendia a se tornar cada vez mais complexo ao longo do tempo. Acompanhando esta tendência, os axiomas da medicina mental passaram a ser cada vez mais apresentados dentro do contexto específico do Judiciário - cujo embasamento era, resguardando-se as respectivas especificidades, tão complexo e distinto quanto o da medicina mental. ${ }^{2}$ Por vezes, verifica-se que o relacionamento entre estas duas comunidades epistêmicas, tão diferentes entre si, gerava situações conflitantes. ${ }^{3}$ Cabe notar que os atritos entre medicina e direito eram intermitentes e se davam principalmente em torno do conceito de custódia que podia ser reivindicada ou negada, ${ }^{4}$ dependendo do caso, por ambas as jurisdições.

Diante do exposto, este trabalho busca revisitar ${ }^{5}$ a luta de Ernestina Ribeiro de Azevedo para se livrar da custódia psiquiátrica, em 1897. A partir deste caso específico, será apresentado o atrito entre medicina e direito em torno do poder

\footnotetext{
${ }^{2}$ Importante deixar claro que o envolvimento entre medicina legal, alienismo e direito foi desenvolvido durante um processo permeado por avanços e retrocessos. Devido a sua complexidade, não cabe fixarmos neste assunto durante o artigo.

${ }^{3}$ Cf. HARRIS, Ruth. Assassinato e loucura: medicina, leis e sociedade no fin de siécle. Rio de Janeiro: Rocco, 1993. FOUCAULT, Michel. Eu, Pierre Riviére, que degolei minha mãe, minha irmã e meu irmão. Rio de Janeiro: Graal, 1997. ENGEL, Magali Gouveia. Os delírios da razão: médicos, loucos e hospícios (Rio de Janeiro 1830-1930). Rio de Janeiro: Editora Fiocruz, 2001. CUNHA, Maria Clementina Pereira da. O espelho do mundo: Juquery a história de um asilo. Rio de Janeiro: Paz e Terra, 1986. BERCHERIE, Paul. Os fundamentos da clínica: história e estrutura do saber psiquiátrico. Rio de Janeiro: Jorge Zahar Editor, 1989.

${ }^{4}$ Talvez a negação da custódia espante alguns leitores. Casos como o do filicida João (1906) e do assassino Oliveira (1909) ilustram a forma como manobras jurídicas punham alguns acusados em liberdade. Durante o decorrer de seus processos, nenhum dos dois foi diagnosticado como alienado. Contudo, a justificativa da brutalidade dos crimes motivou o Judiciário a determinar seus ingressos no Hospício Nacional de Alienados. Os médicos, obedecendo a ordem judicial, os internaram no Pavilhão de Observação. Expirado o prazo da observação, concederam alta e, consequentemente, liberdade a ambos. Ver: PAULA, Richard Negreiros de. Infelizes da praia da Saudade: psiquiatria no Rio de Janeiro da Primeira República. Dissertação de mestrado, PPHG, Universidade Federal Fluminense (UFF), 2006.

${ }^{5} \mathrm{O}$ caso de Ernestina Ribeiro de Azevedo foi brilhantemente tratado por Magali Engel no capítulo V do seu livro: Os delírios da razão: médicos, loucos e hospícios. Rio de Janeiro: Editora Fiocruz, 2001. O presente artigo, contudo, diferencia-se substancialmente do trabalho de Engel ao adicionar novas fontes e trabalhar com hipóteses e problemas diferentes dos elaborados pela referida autora. Aproveito o ensejo para expressar minha sincera admiração e gratidão à autora que muito gentilmente me indicou a localização do processo de Ernestina no Arquivo Nacional. Também não posso deixar de agradecer por ter me oferecido sua rica orientação durante meu mestrado na UFF.
} 
sobre a custódia psiquiátrica, no início do sistema republicano brasileiro. Tal discussão servirá como base para focalizarmos as ideias e ações do médico Teixeira Brandão ${ }^{6}$ referentes a esta temática. Para realizar este intento, o presente artigo apoia-se no postulado de que há uma razão que move a ação dos agentes. ${ }^{7}$ Razão que se deve descobrir para transformar uma série de condutas aparentemente incoerentes, arbitrárias, em uma série inteligível, em algo que possa ser compreendido a partir de um princípio único ou de um conjunto coerente de princípios. No nosso caso, analisaremos a hipótese de que o principal motivo que mobilizou Teixeira Brandão foi a defesa de sua jurisdição profissional diante do que ele considerava uma ameaça: a evidente intromissão dos leigos nas decisões dos médicos alienistas.

Diversos contextos podem se tornar arenas de luta pela manutenção ou expansão da jurisdição profissional. Dentre eles destacam-se a opinião pública e o sistema legal. A primeira constitui-se como campo pela reivindicação da legitimidade social e cultural da profissão, enquanto a segunda estabelece, de forma legal, o controle sobre as atividades profissionais, suas formas de organização e limites legais de atuação. Desta forma, pode-se compreender que é na opinião pública em que são discutidos e solucionados os problemas gerais referentes à jurisdição profissional. Quando tais questões exigem uma maior especificidade analítica, apela-se para a arena legal. Por outro lado, devemos atentar para o fato de que a importância das arenas é relativa a cada contexto social específico. No caso do Brasil fin de siécle, a opinião pública era composta

\footnotetext{
${ }^{6}$ João Carlos Teixeira Brandão (1854-1921). Em 24 de outubro de 1884, foi nomeado facultativo clínico do Hospício Pedro II e, em 27 de fevereiro de 1887, tornou-se diretor do serviço sanitário deste estabelecimento. Em 18 de fevereiro de 1890, foi nomeado diretor geral da Assistência Médico Legal de Alienados e, em 27 de fevereiro de 1897, tornou-se inspetor geral da Assistência a Alienados, ocupando este cargo até 1899. Criou o serviço de avaliação preliminar no Hospício Nacional de Alienados e também se dedicou à legislação sobre alienados, tendo proposto medidas inspiradas nas leis francesa (1838), belga (1850) e inglesa (1897). Procurou, por meio da proposição de dispositivos legais, a correta distinção entre alienados e criminosos. Foi eleito, em 1903, deputado federal pelo Estado do Rio de Janeiro, empenhando-se pela aprovação da legislação que reorganizaria a assistência a alienados no país, concretizada pela promulgação do Decreto $\mathrm{n}^{\circ} 1.132$, de 22/12/1903, que moldava a jurisprudência e a assistência a alienados no país. Cf.: Dicionário histórico-biográfico de saúde no Brasil (1932-1930). Casa de Oswaldo Cruz/ Fiocruz - (http:// www.dichistoriasaude.coc.fiocruz.br). Acesso em 27/04/2007.

${ }^{7}$ De acordo com Pierre Bourdieu, os agentes sociais "podem se conduzir de tal maneira que, em uma avaliação racional das probabilidades de sucesso, pareça que eles tinham razão em fazer o que fizeram, sem que tenhamos razão ao dizer que o cálculo racional das probabilidades tenha sido o princípio das escolhas que fizeram". BOURDIEU, Pierre. Razões práticas: sobre a teoria da ação. Campinas, São Paulo: Papirus, 1996, p. 138-140.
} 
majoritariamente por membros da elite. Daí, muitas das discussões travadas neste âmbito foram levadas rapidamente à arena legal. Desta forma, o presente artigo pretende dirigir sua atenção substancialmente a esta última arena.

Embora esteja focalizado na disputa travada por Teixeira Brandão pela manutenção ou, dependendo do ponto de vista, ampliação da jurisdição profissional dos médicos alienistas, este texto também tocará em pontos que são de fundamental importância para a análise do período subsequente ao caso Ernestina. O primeiro refere-se à disputa entre juristas e médicos, travada no âmbito da arena legal, pelo domínio sobre a custódia dos insanos. Este debate, por consequência, evidenciou a clara necessidade de que a diferenciação entre loucos e sãos estivesse pautada sobre bases mais concretas. ${ }^{8}$ Tal separação pôs em relevo um segundo problema. Conforme será demonstrado, o dilema de Ernestina representou um incremento à construção de um conjunto de determinações que visavam diferenciar a clientela específica que cabia à justiça e à medicina. Este processo se deu por meio de lutas abertas, influenciadas em maior ou menor grau, dependendo do contexto, pela atuação de forças externas a cada uma das respectivas jurisdições profissionais. Por isso, a importância da separação se remete, na prática, ao fato de que é o cliente quem confere o grau de legitimidade a cada grupo. Daí a necessidade do estabelecimento de fronteiras menos fluidas.

Cabe destacar o fato de que Teixeira Brandão, ciente ou não desta assertiva, dedicou-se ao resguardo do poder psiquiátrico sobre sua clientela, separando justamente os insanos dos demais tipos sociais, e chamando para a psiquiatria a competência sobre eles. Podemos citar como exemplos concretos: seu empenho na elaboração e aprovação do Decreto ${ }^{\circ}$ 1.132, de 22 de dezembro de 1903, considerada, no Brasil, a primeira lei geral de jurisprudência sobre alienados; a fundação da Sociedade de Jurisprudência Médica e Antropológica (1897); e por fim sua luta pela criação do Manicômio Judiciário, concretizada em 1921.

\section{II}

Não é raro, para o historiador, encontrar exemplos de fatos particulares que suscitam tantos questionamentos a ponto de modificarem normas que à primeira vista pareciam consolidadas. Neste caso, os responsáveis pela elaboração

\footnotetext{
${ }^{8}$ A intenção de alcançar a solidificação dos critérios de identificação da alienação mental não significa necessariamente que esta tivesse sido alcançada.
} 
do dispositivo que condicionava a reclusão manicomial ao exame do médico alienista, publicado em agosto de 1897, estiveram diretamente influenciados pela discussão gerada pelo julgamento sobre a situação de Ernestina Ribeiro de Azevedo. Este dispositivo será mais bem discutido adiante, quando forem apresentadas as disposições legais que regiam a custódia psiquiátrica. Cabe ressaltar desde já que o caso Ernestina foi decisivo para trazer à tona algumas das principais falhas no funcionamento da lei de alienados, ainda pautada no artigo 311 das leis civis do Império. ${ }^{9}$

$\mathrm{O}$ efeito mais imediato ocasionado pela disputa jurídica levada a cabo por Ernestina, segundo Brandão, referiu-se ao "desconcerto de opiniões sobre a matéria, que não pode deixar de ser prejudicial aos interesses individuais e da coletividade, quase sempre, em tais casos, em conflito". ${ }^{10}$ Para dar conta de tais controvérsias, "a Câmara dos Deputados aprovou, em $3^{\text {a }}$ discussão, um projeto de lei sobre alienados que já se acha no Senado para ser discutido". Tal assertiva evidencia que este médico elaborou seu relatório, enviado ao ministro da Justiça, ainda durante o processo de discussão da lei de agosto de 1897, marcando clara posição quanto às suas opiniões sobre o tema. Desta forma, conforme já exposto, o presente trabalho propõe a análise dos argumentos utilizados pelo médico Teixeira Brandão na defesa da exclusividade do médico alienista na avaliação dos casos de alienação mental e no consequente domínio sobre a custódia psiquiátrica. Para cumprir esta intenção, serão utilizados dois documentos principais: o processo de Ernestina de Azevedo e o relatório enviado por Teixeira Brandão ao ministro da Justiça, ambos de 1897.

Os documentos citados indicam que o caso Ernestina pôs em xeque o delicado equilíbrio entre os poderes médico e jurídico no que concerne à custódia psiquiátrica. Esta hipótese pode ser comprovada através do relatório elaborado pelo próprio Teixeira Brandão. Neste documento, ele afirmou que o caso de Ernestina foi o pivô de inúmeras discussões, tanto na imprensa quanto na Câmara e no Senado, acerca da legalidade de sua internação no Hospício Nacional de Alienados. Contudo, este trabalho pouco vai se ater às discussões e polêmicas suscitadas pelo caso. Tal escolha se dá por um motivo simples: a intenção é expor e analisar o ponto de vista de um único médico, Teixeira

\footnotetext{
${ }^{9}$ As leis civis do Império vigoraram até 1916, quando foi promulgado o Código Civil.

${ }^{10}$ Obtido via base de dados do Projeto de Imagem de Publicações Oficiais Brasileiras do Center for Research Libraries e Latin-American Microfilm Project. Disponível na internet: http:/wwwcrl. uchicago.edu/info/brazil/pindex.htm. Acesso em 27/04/2007.
} 
Brandão, sobre uma questão específica: a legitimidade da internação promovida pelos psiquiatras.

Ernestina Ribeiro de Azevedo, branca, 28 anos, casada, natural da cidade de Campos, pertencente a uma família tradicional desta cidade - era filha de um visconde -, foi internada no Hospício Nacional de Alienados ${ }^{11}$ no dia 7 de março de 1897. Antes, segundo descrito no processo, esteve internada no hospício de Barbacena ${ }^{12}$ a conselho de Cipriano de Freitas, médico bastante respeitado à época. Ernestina foi conduzida ao HNA sem estar ciente das reais intenções do marido: Sebastião de Vasconcelos Azevedo. Sua internação foi efetuada sob pretexto de "precisar de observações sobre seu estado mental". ${ }^{13}$ Contrariada com esta situação, Ernestina lançou mão dos serviços do advogado Carlos Augusto de Carvalho. ${ }^{14}$

Uma vez aceito o caso de Ernestina, a providência inicial, tomada pelo advogado, foi impetrar um pedido de habeas corpus ${ }^{15}$ junto ao juiz do Tribunal Civil e Criminal, em 22 de abril de 1897. A principal alegação consistiu em demonstrar que sua cliente se encontrava em "perfeitas condições de equidade mental e, quando não estivesse, só por autoridade da Justiça poderia ser privada da liberdade no caso de ser incompatível com a segurança pública". ${ }^{16}$ Assim, percebe-se que o instrumento legal acionado por Augusto Carvalho referiuse diretamente ao monopólio da decisão sobre a custódia que, legalmente,

\footnotetext{
${ }^{11}$ Daqui por diante será referido como HNA.

${ }^{12}$ Infelizmente o documento não informa o período em que Ernestina teria permanecido nesta instituição.

${ }^{13}$ Processo Ernestina Ribeiro de Azevedo, habeas corpus no 2.954 , caixa 7.624, maço 926, galeria A, 1897, Arquivo Nacional.

${ }^{14} \mathrm{O}$ caso de Ernestina Ribeiro de Azevedo foi brilhantemente apresentado e discutido por Magali Engel em Os delírios da razão.

${ }^{15}$ De acordo com Marcellino da Gama Coelho: "o habeas-corpus é o remédio que a lei concede contra violência ao direito civil da liberdade pessoal. Esta definição caracteriza que o habeas-corpus é: $1^{\circ}$, um procedimento ou processo especial. $2^{\circ}$, de uma natureza sui-generis. Não é um recurso no estrito sentido judiciário, empregado como meio de reformar decisão pronunciada. É um novo processo, de ordem jurídica, de natureza sumária, diverso do ato que o originou. É um recurso extraordinário a uma violência dada, na falta de outro que a faça desaparecer, ou a evite. Quando empregado no sentido de recurso propriamente dito, é já de decisão proferida, em procedimento instaurado. Neste caso espécie do gênero. É de uma natureza sui-generis porque tem aplicação nas relações do direito criminal, em que é mais comum, nas do direito civil, do direito político e do direito administrativo. A definição dada tem fundamento na Constituição, nas leis anteriores do antigo regime (Império), nos princípios e fundamentos desta instituição”. Cf: COELHO, Marcellino da Gama. Do habeas-corpus. Rio de Janeiro: Typographia Guimarães, 1900, p. 05.

${ }^{16}$ Processo Ernestina Ribeiro. Ibidem.
} 
deveria ser exercido somente pelo aparato judiciário. Como fundamento para suas argumentações, Carvalho lançou mão dos preceitos que estruturavam o edifício jurídico da jovem República para afirmar que "é a autoridade judicial quem, causa cognita, decide se a perturbação mental, quando efetiva, autoriza a interdição legal para acautelar a fazenda e bens e simultaneamente a internação em um hospital como ato de humanidade ou de cautela social". ${ }^{17}$

De outra forma, podemos avaliar que o advogado lançou mão de três estratégias complementares de defesa: a primeira consistia em argumentar que sua cliente não sofria de nenhuma moléstia mental - afirmativa que foi reiterada durante a redação de sua petição; em seguida verifica-se a alegação de que não havia indícios de que Ernestina representasse perigo aos seus bens ou à sociedade; finalmente, talvez mais relevante que os dois primeiros, o advogado baseou-se na defesa do exclusivo poder jurídico sobre a prática tutelar e a consequente arbitrariedade na internação de sua cliente. Desta maneira, caso Ernestina sofresse todos os exames periciais e fosse realmente avaliada enquanto alienada, ainda assim a decisão de sua tutela não deveria caber aos médicos, mas sim ao juiz, que finalmente decidiria seu destino. Importante notar que este último argumento punha à mostra a contenda que havia entre médicos e juristas quanto à autoridade da decisão sobre a reclusão dos insanos.

Por sua vez, Márcio Nery, médico do HNA, também se embasou nos dispositivos legais para justificar o ingresso de Ernestina na qualidade de "paciente em observação". Para tanto, como contra-argumento, lançou mão do que foi determinado pelo artigo 87, do Decreto $\mathrm{n}^{\circ} 2.467$, de 19 de fevereiro de 1897: "todos os indivíduos que, pela prática de atos indicativos de alienação mental, tiverem de ser recolhidos ao Hospício, ali darão entrada provisória até se verificar alienação nos termos do parágrafo $n^{0}$ VII do artigo 47". ${ }^{18}$ Prosseguindo na sua leitura da lei, Nery completou lembrando que "a matrícula realiza-se há 15 dias depois da entrada dos enfermos, salvo casos especiais, em que, a juízo do médico em chefe deva este prazo ser prorrogado". ${ }^{19}$ Além disso, Nery confirmou que foi Sebastião, marido de Ernestina, quem tomou a iniciativa de conduzi-la ao HNA para que fosse observada pelos médicos psiquiatras. Este

\footnotetext{
${ }^{17}$ Ibidem.

${ }^{18} \mathrm{O}$ referido parágrafo profere o seguinte: “Apresentar ao médico em chefe, no prazo de 15 dias, que poderá ser por ele prorrogado, um parecer por ele fundado nos exames que houverem feito sobre o estado mental dos enfermos em observação".

${ }^{19}$ Processo Ernestina Ribeiro. Ibidem.
} 
fato fazia cumprir o que era postulado pelo artigo $\mathrm{n}^{\circ}$ 91, do mesmo decreto: "são competentes para requerer a admissão (no HNA) de enfermos, quer contribuintes quer gratuitos: $1^{\circ}$ - ascendente ou descendente; $2^{\circ}$ - o cônjuge; $3^{\circ}-o$ tutor ou curador; $4^{\circ}$ - o chefe de corporação religiosa". Assim, Nery também pôs a lei a favor de Sebastião e dos médicos do Hospício, eximindo-os da possibilidade de haverem cometido alguma arbitrariedade no ato de internarem Ernestina.

Sobre a legitimidade da internação de Ernestina, Márcio Nery depôs que "acerca da suspeita de que se trata de um caso de alienação há a opinião de médicos proeminentes que a observaram e trataram antes de sua internação no Hospício, podendo entre outros indicar os diretores do Sanatório de Barbacena, um dos quais é distinto especialista em moléstias mentais". ${ }^{20} \mathrm{O}$ médico ainda acrescentou que o "vício assaz carregado de que d. Ernestina Ribeiro de Azevedo é portadora e os próprios antecedentes individuais" constituíam-se como critérios científicos de diagnóstico que, aliados à palavra dos médicos de Barbacena, compunham razões suficientemente científicas para justificar a internação de Ernestina. Lembremos, contudo, que as lentes do Judiciário poderiam ler tais alegações de modo bastante diferente daquele pretendido pelo médico, uma vez que a avaliação feita pelos alienistas deveria ser avalizada pelo juiz.

Contudo, o advogado Carlos Carvalho reuniu novos elementos que foram fundamentais no rumo do processo. Dentre estes, destacamos os depoimentos do facultativo clínico e de uma enfermeira do HNA.

Contrariando Márcio Nery, o facultativo clínico do HNA, dr. Francisco Cláudio de Sá Ferreira, não parecia tão seguro quanto ao estado mental de Ernestina. Por isso, declarou que, até 23 de abril, não havia observado qualquer sinal que possibilitasse uma avaliação precisa, quer favorável, quer desfavorável, de sua saúde. A opinião do médico Francisco Cláudio baseava-se coerentemente no fato de que o período de tempo em que Ernestina permaneceu em observação não havia excedido o limite estipulado em lei. ${ }^{21}$

Já a enfermeira do HNA, Josephina Quirina, depôs que nunca observou qualquer sinal de desarranjo nas faculdades mentais de Ernestina. Ao contrário, conforme depoimento prestado pela enfermeira, Ernestina havia se revelado "uma senhora muito inteligente" e de "bom gênio", parecendo-lhe, portanto,

\footnotetext{
${ }^{20}$ Ibidem.

${ }^{21}$ Lembrando que a lei de fevereiro de 1897 estipulava quinze dias iniciais que poderiam ser prorrogados por mais quinze, totalizando trinta dias de observação.
} 
ser ela uma pessoa de perfeita integridade mental e moral. De acordo com os autos do processo, Josephina tinha tanta convicção na sua opinião a ponto de ter ameaçado pedir demissão caso Ernestina fosse tida como louca.

Assim, podemos concluir que ambas as partes estavam em concordância com as determinações legais, embora o diagnóstico clínico ainda se mantivesse sob discussão entre os especialistas. Se, por um lado, o advogado se valeu do postulado de que a reclusão era objeto exclusivo do Judiciário, por outro, os médicos do HNA se valeram do que estava determinado nas leis sobre alienados, especialmente no Decreto $\mathrm{n}^{\circ} 2.467$. Como este conflito foi resolvido?

Respeitado o procedimento padrão de se ouvir ambas as partes e os respectivos depoentes, o juiz Affonso de Miranda considerou que o fato "de ter sido a reclusão levada a efeito pelo marido da paciente, que com ela vivia em desarmonia conjugal, e que para esse fim teve de surpreender-lhe a boa fé...", ${ }^{22}$ foi suficiente para que decidisse a favor de Ernestina. O mesmo juiz, enfim, julgou o caso sob um argumento pouco utilizado pela defesa de Ernestina e muito mais explorado pelos médicos do HNA. Conforme discutiremos adiante, o cônjuge tinha pleno direito de requerer uma avaliação sobre o estado de saúde mental de sua companheira e que, por isso mesmo, os médicos do HNA alegavam que não foi praticado nenhum ato ilegal. Contudo, o juiz atentou para o ponto de que ao marido, Sebastião Azevedo, interessaria manter reclusa a esposa que lhe promovia embaraços conjugais. Por isso, o juiz considerou que Sebastião lançou mão de métodos espúrios, lesando a boa fé que Ernestina lhe depositava. Além disso, Affonso de Miranda também considerou arbitrária a reclusão de Ernestina, pois esta decisão não havia sido avalizada por um juiz.

Atentemos para o fato de que a sentença do juiz pouco levou em conta as considerações dos médicos mais "proeminentes" sobre o estado de saúde mental de Ernestina. ${ }^{23}$ Para Brandão, esta decisão representou um duro golpe em suas convicções sobre o papel dos médicos e de sua ciência. De forma irônica, o médico afirmou que estavam "invertidos os papéis, ao magistrado competirá o diagnóstico e ao médico a aquiescência à douta opinião do juiz!" 24 Apoiado no seu olhar de perito, que julgava enxergar para além dos sintomas analisados pelos leigos, Teixeira Brandão argumentou que: "não deixarei de lembrar para

\footnotetext{
${ }^{22}$ Processo Ernestina Ribeiro de Azevedo, op cit.

${ }^{23}$ Importante esclarecer que este fato não desrespeitava as normas legais vigentes.

${ }^{24}$ Relatório enviado ao Ministério da Justiça, referente ao ano de 1897, p. 393.
} 
esclarecimento do assunto e demonstração dessa absurda hermenêutica, que as formas as mais perigosas, as impulsivas, por exemplo, darão lugar à aplicação daquele recurso legal, por isso, ao juiz, sempre parecerá são o indivíduo que raciocina logicamente, já que para ele não existe outro critério diagnóstico senão o delírio". ${ }^{25}$

\section{III}

No início do período republicano, em janeiro de 1890, apenas dois meses após sua instauração, uma primeira reforma legal criou a Assistência Médica e Legal de Alienados, ${ }^{26}$ e desanexou o Hospício Nacional de Alienados da Santa Casa de Misericórdia do Rio de Janeiro. ${ }^{27}$ Além disso, esta mesma reforma também foi responsável por algumas mudanças no estatuto do HNA que, dentre outros pontos, definiu: "todas as pessoas que, por alienação mental adquirida ou congênita, perturbarem a tranquilidade pública, ofenderem a moral e os bons costumes, e por atos atentarem contra a vida de outrem ou contra a própria, deverão ser colocados em asilos especiais, exclusivamente destinados à reclusão e ao tratamento de alienados" ${ }^{28}$ O decreto anterior, ${ }^{0}$ 1.077, de 04/12/1852, contudo, previa que os responsáveis pelo antigo Hospício de Pedro II (posterior HNA) deveriam respeitar as seguintes premissas para proceder a internação: “( $\left.\operatorname{art} 10, \S 1^{\circ}\right)$ à vista de requisição oficial do juiz de Órfãos, ou do chefe ou do delegado de Polícia do distrito da residência do alienado ou onde for encontrado; e sendo militar, eclesiástico ou religioso, do seu superior competente". Caso a iniciativa partisse do âmbito privado, o requerimento da internação caberia "ao pai, tutor ou curador, irmão, marido ou mulher, ou senhor do alienado, por ele assinada, com reconhecimento da assinatura por tabelião ( $\operatorname{art} 10, \S 2^{\circ}$ )" .

Podemos perceber sutis, mas importantes, diferenças ao compararmos ambas as leis. Primeiro cabe atentar para a expressão "alienação mental adquirida ou congênita” que era inexistente na lei de 1852. A inclusão desta frase assinala o

\footnotetext{
${ }^{25}$ Ibidem.

${ }^{26}$ De acordo com o Decreto n ${ }^{\circ} 206$ A, de 11/01/1890, a Assistência Médica e Legal dos Alienados era composta pelo HNA e pelas colônias Conde de Mesquita e São Bento.

${ }^{27}$ O curto período de tempo entre a proclamação da República (15/11/1889) e a aprovação da lei que desanexava o HNA da Santa Casa de Misericórdia assinala o bom grau de influência política exercida pelo grupo de alienistas, dentre os quais figura Teixeira Brandão, no início da República. Cf. ENGEL, Magali. Ibidem.

${ }^{28}$ Artigo 13, do Decreto n ${ }^{\circ} 206$ A, de 15 de fevereiro de 1890.
} 
pano de fundo da cientificidade presente no discurso e na prática dos alienistas. A principal consequência deste fator foi a elevação no grau de apropriação da loucura pela medicina. Outra questão importante está ligada à frase "perturbarem a tranquilidade pública, ofenderem a moral e os bons costumes". O período imperial mostrou-se bem mais permissivo que a República em relação aos alienados mentais que vagavam pelas ruas com suas atitudes "excêntricas". Neste sentido, alguns personagens que compunham o cenário urbano da corte tiveram suas atitudes medicalizadas no contexto republicano. De fato, podemos afirmar que foi ampliado o leque de possibilidades que expunham os indivíduos à internação asilar.

Além dessa, outras cinco reformas foram responsáveis por mudanças nas leis que regulamentavam a assistência aos alienados, ${ }^{29}$ até que se formulasse a primeira lei federal sobre o tema, em 1903. Esta última lei começou a ser discutida logo após o desfecho do caso Ernestina que influiu de modo decisivo na sua redação.

Embora alguns pontos do estatuto do HNA já tivessem sofrido alterações, em 1897, ano do ingresso de Ernestina Ribeiro no HNA, as custódias e interdições exercidas pelos médicos alienistas ainda encontravam respaldo nas determinações das leis civis do Império, baseando-se, sobretudo, no artigo $n^{0} 311$. Este fixava que: "logo que o juiz de órfãos souber que em sua jurisdição há algum demente, que pela loucura possa fazer mal, entregá-lo-á a um curador que administre sua pessoa e bens" ${ }^{30}$ Complementando este dispositivo legal, firmou-se a exigência da realização de um exame de sanidade, elaborado por um profissional médico. Para tanto, o Decreto $\mathrm{n}^{\circ} 1.740$, de 16 de abril de 1856, havia criado, junto à Secretaria de Polícia da corte, uma seção de assessoria médica destinada a proceder aos "corpos de delito e quaisquer exames médicos necessários para a averiguação dos crimes e dos fatos tais como suspeitados". ${ }^{31}$

29 Decretos $n^{\circ}$ s: 508 , de 21/06/1890; 896, de 29/06/1892; 1.559, de 07/10/1893; 2.467, de 19/02/1897; 3.244, de 29/03/1899. Os decretos citados não serão discutidos em profundidade, pelo fato de que a análise detida seria demasiado longa e não contribuiria significativamente para alcançarmos os objetivos finais deste texto.

${ }^{30}$ Consolidação das Leis Civis do Império, art. 311.

${ }^{31}$ PEIXOTO, Afrânio. Medicina legal. 4a ed., 1923, p. 398. Apud: RAMOS, Arthur. Loucura e crime: questões de psychiatria, medicina forense e psychologia social. Porto Alegre, Rio Grande do Sul: Edições Globo, 1937, p. 191. 
Porém, de acordo com Afrânio Peixoto, ${ }^{32}$ quando se tratava de exame de sanidade mental, o Serviço Médico Legal apresentava diversas falhas no seu funcionamento. Conforme verificamos ao longo do texto, alguns pontos frágeis do Decreto $\mathrm{n}^{\circ} 1.740$ ficaram bastante evidentes ao longo do ano de 1897 . Por este motivo, em agosto deste mesmo ano, após o fim do processo Ernestina, foi criado um novo dispositivo de regulamentação para o Serviço de Assistência a Alienados. Dentre outros pontos, firmou-se que "sob pretexto de alienação mental, ninguém será internado em estabelecimento de alienados ou privado da liberdade sem exame prévio que demonstre tal enfermidade". ${ }^{33}$ Ou seja, a lei reiterou a condição de que a internação deveria se realizar em caráter provisório, até que um diagnóstico fosse elaborado pelos médicos peritos. Contudo, juridicamente manteve-se estabelecido que o exercício da decisão sobre qualquer tipo de custódia era função de exclusivo domínio do Judiciário.

Segundo Andrew Abbott, ${ }^{34}$ existem diferentes meios para se promover a manutenção da plena jurisdição profissional. Uma delas está calcada na cultura da autoridade profissional. Neste sentido, a custódia psiquiátrica representou uma tensa zona de fronteira na demarcação dos limites entre medicina e direito. Na opinião de Brandão, a atuação do Judiciário sobre as decisões psiquiátricas representava uma perigosa intromissão num campo em que todos, exceto os alienistas, eram leigos. Importante observar que este conflito possui um caráter intermitente, pois girava em torno de um único ponto específico: a questão da custódia sobre os alienados mentais. Outro ponto que se deve alertar está relacionado ao fato de que este tipo de conflito não ficou restrito ao contexto da Primeira República brasileira. Longe de ser uma querela paroquialista entre alienismo, medicina legal e direito, os problemas enfrentados pelos personagens brasileiros, aqui apresentados, eram bastante parecidos com os de seus congêne-

\footnotetext{
${ }^{32}$ Júlio Afrânio Peixoto (1876-1947). Foi inspetor de Saúde Pública (1902) e diretor do Hospital Nacional de Alienados (1904); após concurso, foi nomeado professor de Medicina Legal da Faculdade de Medicina do Rio de Janeiro (1907) e assumiu os cargos de professor extraordinário da Faculdade de Medicina (1911); diretor da Escola Normal do Rio de Janeiro (1915); diretor da Instrução Pública do Distrito Federal (1916); deputado federal pela Bahia (1924-1930); professor de História da Educação do Instituto de Educação do Rio de Janeiro (1932). No magistério, chegou a reitor da Universidade do Distrito Federal, em 1935. Obtido via: Psychiatry on line Brasil http://polbr.med.br/ano02/wa10802.php Ver também: Academia Brasileira de Letras - http://www. academia.org.br . Ambos foram acessados em 27/04/2007.

${ }^{33}$ Anais da Câmara dos Deputados, ago. 1906.

${ }^{34}$ ABBOTT, Andrew. The system of professions: an essay on the division of expert labor. University of Chicago Press.
} 
res europeus e sul-americanos. ${ }^{35}$ Ciente disso, Teixeira Brandão se aprofundou nos estudos das soluções legais sobre alienados, adotadas por países como: França (1838); Bélgica (1850) e Inglaterra (1897).

É importante alertar para o fato de que a custódia sobre os alienados, contudo, abriu um leque de discussão sobre questões que interferiam tanto na teoria quanto na prática da medicina e do direito. Para ser submetido a um exame de sanidade mental, um cidadão deveria solicitá-lo ou ter sido intimado a fazê-lo mediante processo judicial constituído. Neste sentido, o indivíduo que cometeu algum delito e era tido como alienado tinha chances de escapar, de certa forma, do binômio crime e castigo, característico do direito ocidental à época. ${ }^{36}$

\section{IV}

O século XIX foi um período que presenciou o florescimento de inúmeras instituições psiquiátricas, tanto no Brasil quanto na Europa e em alguns países das Américas. Como resultado desta ampliação na quantidade de estabelecimentos dedicados ao estudo e tratamento sistemáticos da alienação mental, passou-se a formar uma rede de troca de informações que permitiu a ampliação do leque de conhecimento disponível aos alienistas. Por parte dos médicos, coube codificar a loucura enquanto doença. Isto é, tornar patológico o comportamento desviante. Vários tipos de comportamentos antissociais ou não disciplinados, juntamente com as disposições fisiológicas, como intoxicações e as degenerescências que lesionam o sistema nervoso central, passaram a ser alvos de análise do discurso alienista. Soma-se a isto o fato das novas teorias baseadas na neurologia também representarem um incremento no senso de clientela dos alienistas. Conforme já apresentado, verifica-se a aplicação de tais premissas já na formulação da primeira reforma da lei sobre alienados mentais, em 1890. Portanto, se em um período anterior, o delírio era a principal forma de reconhecimento da loucura, a sistematização do saber alienista ampliou sua determinação e, por consequência, buscou vedar seu sistema de diagnóstico ao olhar do leigo.

A legitimação do conhecimento especializado foi bastante favorecida pela ampliação do leque de moléstias estudadas, fazendo com que a alienação pas-

\footnotetext{
${ }^{35}$ Cf.: HARRIS, Ruth. Ibidem; SKALEVAG, Svein Atle. The matter of forensic psychiatry: a historical enquire. In: Medical history. 2006, 50; DI LISCIA, Maria. Médicos, jueces y locos. Sobre peritaje de insania y justicia en el interior argentino, 1890-1930.

${ }^{36}$ HARRIS, Ruth. Ibidem.
} 
sasse a ser cada vez mais um objeto visível somente aos olhos dos especialistas. Assim, pode-se dizer que a produção de conhecimento científico referente à loucura, ao mesmo tempo em que embasou e conferiu relativa legitimidade, também fomentou a reivindicação médica sobre a exclusiva jurisprudência sobre os discursos e práticas que se relacionavam aos males mentais. Como resultado, devemos enfocar o aumento da distância estabelecida entre o saber "científico" em relação às ideias do senso comum. O merecimento do destaque reside no fato de que, para Teixeira Brandão, as opiniões leigas não possuíam legitimidade, pois não estavam embasadas nos ideais de cientificidade que estruturavam o campo psiquiátrico. Ou seja, para este médico há crenças sobre a loucura, de um lado, e, de outro, existe o conhecimento genuíno, sistematizado e objetivo.

Contudo, as divergências entre os médicos Márcio Nery e Francisco Ferreira expuseram a precária uniformidade que ainda subsistia no sistema de diagnóstico alienista. Este fato contradiz fortemente a opinião de Brandão de que o alienismo era, até então, sistemático e objetivo. De fato, é necessário salientar que as investigações levadas a cabo nos arquivos do Hospital Nise da Silveira (antigo HNA) mostram que muitos pacientes recebiam diferentes diagnósticos ao longo de sua vida asilar. Por isso, apesar do processo de solidificação do conhecimento alienista ter sofrido significativos incrementos ao longo do século XIX, devemos lembrar que ainda não havia base suficientemente forte que sustentasse a uniformidade do diagnóstico ou laudo médico-legal realizado pelos alienistas. O caso Ernestina, portanto, deixou bastante claro que eram necessárias mudanças e adaptações, tanto nas leis quanto nos métodos empregados nos exames. Neste sentido, o Decreto n ${ }^{\circ} 4.864$, de 15 de junho de 1903, representou uma iniciativa de que fosse firmado um conjunto de critérios que uniformizassem os dados necessários ao estabelecimento do diagnóstico que justificasse a iniciativa da internação, respeitando a premissa de que a reclusão seria realizada apenas nos casos de alienação mental. Nele, ficou definido que "os exames médico-legais proceder-se-ão mediante ordem da autoridade competente incumbida da elaboração de um corpo de delito ou por qualquer motivo interessada para a investigação policial". ${ }^{37}$

Como é possível verificar no quadro em anexo, a referida lei inovou ao especificar uma série de itens que seriam examinados e respondidos pelos médicos responsáveis pela peritagem. Imaginava-se que o balanço destes dados daria

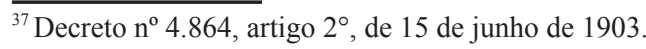


condições para que se realizasse um julgamento com maior grau de exatidão sobre a situação mental do indivíduo analisado. Assim, além de servir como base de argumentação jurídica, este conjunto de regras de conduta também funcionou como meio de se fortalecer a autoridade médica mediante uma imagem pública que realçava a competência científica dos diagnósticos psiquiátricos.

Ao que indica o relatório de 1897, Brandão tinha o importante apoio de Prudente de Moraes. Talvez por isso tenha transcrito uma parte do pronunciamento que o presidente havia dirigido ao Senado, um ano antes. Nele, Moraes se mostrou contrário aos rumores de que o Hospício Nacional ficaria novamente sob a direção da Santa Casa de Misericórdia do Rio de Janeiro. O principal argumento do presidente estava assentado sobre a ideia de que o HNA "não pode deixar de estar sob a alçada do poder público, que é o único competente para estabelecer restrições à liberdade individual e fixar os efeitos que decorrem, em relação à família e à sociedade, dessa medida excepcional. Daí a necessidade indeclinável, e uniformemente reconhecida por todas as nações, da organização da assistência aos alienados". ${ }^{38}$ Tal raciocínio, também comungado por Brandão, fez com que os médicos esbarrassem substancialmente no papel do Poder Judiciário, tendo a custódia como elemento central da controvérsia. Afinal, de acordo com o sistema jurídico da época, o Judiciário era o único poder capaz de decidir sobre a custódia dos indivíduos.

Porém, ao explicitar o fato de que o aparato legal comportava brechas que permitiam aos alienistas exercerem a custódia médica, entendemos por que Ernestina era uma exceção ao que parecia ser uma constante. Pois, na imensa maioria dos casos analisados nos arquivos do antigo HNA, os indivíduos conduzidos a uma instituição psiquiátrica não tinham sequer acesso aos recursos jurídicos existentes. Afinal, para os alienistas, cabia aos médicos reconhecer as manifestações da loucura, cujas repercussões tornavam-na objeto de investigações e explicações científicas que separaram o alienado de outros elementos desviantes, como criminosos e malfeitores, onde o recolhimento a estabelecimentos especiais impôs-se sob a ideia desta ser uma prática terapêutica com o objetivo de tratar, curar - quando possível - e proteger o louco e a sociedade. Cabe, no entanto, lembrarmos que os parâmetros definidores de sua ação ainda não estavam plenamente formalizados pelo sistema jurídico-legal.

\footnotetext{
${ }^{38}$ Relatório anual enviado ao ministro da Justiça, relativo ao ano de 1896.
} 
Diferente do que é sugerido por alguns autores, este tipo de prática não era aplicada somente às mulheres ou aos desvalidos como forma de controle social, mas, ao contrário, era comum a qualquer indivíduo. Além disso, também não pode ser empregada a ideia de um controle que parte dos médicos para o conjunto da sociedade. Por isso, é importante lembrar que desde antes de Pinel, mas com maior fôlego depois da divulgação de suas ideias e a consequente sistematização médica da prática asilar, havia a concepção de que o louco agia sob uma determinada forma de alteração comportamental que punha em risco suas relações sociais. Por isso, pode-se afirmar que a reclusão do delirante antecedeu a medicalização do louco. Daí a reclusão e o isolamento, num primeiro momento, serem ferramentas que visavam proteger o próprio louco e a sociedade para, depois, se tornarem condições centrais do tratamento médico.

Verifica-se que as ideias calcadas sobre o controle social exercido pela psiquiatria são bastante recorrentes entre muitos pesquisadores que lidaram com o tema. As conclusões destes autores dão a impressão de que o caráter científico e o propósito da cura foram secundários frente à intenção de excluir os elementos que causavam incômodo à sociedade. Foucault, por exemplo, no livro Em defesa da sociedade, ${ }^{39}$ acreditou que o principal ponto de interesse da psiquiatria era o conjunto dos mecanismos pelos quais o alienado é controlado, seguido, punido e reformado. Joel Birman é outro autor que segue a linha que credita à psiquiatria o binômio controle/exclusão. Expondo sua ideia de forma bastante consonante à de Erving Goffman, ${ }^{40}$ Birman afirmou que a psiquiatria visava à contenção da "periculosidade física, moral e social, assim como a proteção dos bens públicos e privados, o alcoolismo e a indigência". ${ }^{41}$ Maria Clementina da Cunha também se valeu da ideia de que a psiquiatria esteve ligada de forma indelével às intenções de controlar e excluir os que incomodavam os interesses dominantes. Segundo esta autora, os psiquiatras brasileiros, especialmente os paulistas, no início do século XX, lançaram mão das referências provindas do cabedal teórico europeu, pois "permitiram a medicalização de um amplo

\footnotetext{
${ }^{39}$ FOUCAULT, Michel. Em defesa da sociedade. São Paulo: Martins Fontes, 1999.

${ }^{40}$ GOFFMAN, Erving. Manicômios, prisões e conventos. São Paulo: Perspectiva, s.d. Nesta obra, Goffman analisa a vida em instituições totais e mostra como este tipo de segregação atua sobre o indivíduo. Sua análise sobre o manicômio tenta explicar por que o comportamento do doente mental em face da instituição diz respeito muito mais à sua condição de internado do que propriamente à sua doença.

${ }^{41}$ BIRMAN, Joel. A psiquiatria como discurso da moralidade. Rio de Janeiro: Graal, 1978, p. 258.
} 
repertório de comportamentos sociais e pessoais que se afastavam das normas da moral e da disciplina - e o parentesco da loucura com o crime, a imagem de sua periculosidade lentamente construída pelo saber psiquiátrico, constituem aí instrumentos básicos, ao colocar sob suspeita indivíduos e setores sociais incômodos". 42

Pode ser afirmado que o conhecimento científico está profundamente enraizado nas condições sociais e históricas que o produziu. Desse modo, tanto a sintomatologia quanto o tratamento de qualquer doença mental também encontraram seu ponto de apoio na vida social. Por isso, admite-se aqui o fato de que uma ciência que propunha a disciplina social como forma de prevenção e/ou terapêutica seria interessante aos grupos sociais que formavam a elite do poder. Talvez este fator tenha sido decisivo nos trabalhos históricos e sociológicos que deram especial ênfase ao estabelecimento de alianças entre a psiquiatria e uma série de outros poderes, no sentido de amplificar o controle sobre os corpos e as ações individuais e coletivas. Por outro lado, não é possível subordinar totalmente o sentido que moveu o "fazer ciência" - cuja essência pode ser interpretada como sendo uma pretensão à verdade - aos cânones sociais. $\mathrm{O}$ estudioso que pretende investigar a história do conhecimento científico deverá conceber não somente o enraizamento do conhecimento na sociedade e a interação conhecimento/sociedade, mas, sobretudo, o circuito fechado no qual o conhecimento foi produto/produtor de uma realidade sociocultural que comportou uma dimensão cognitiva. Por isso, é correto asseverar que houve na psiquiatria inegáveis características de controle e exclusão em relação às atitudes sociais. Contudo, não se pode alicerçar explicações sobre o tema somente em bases firmadas nestes parâmetros. Afinal, por trás do discurso e das ações dos psiquiatras, havia uma epistemologia científica que definia as formas de observação, e as regras de produção e arbitragem dos enunciados particulares da alienação mental (diagnóstico, prognóstico e terapêutica).

Pesquisas no arquivo do antigo HNA revelam que era comum os seus médicos dificultarem ou até mesmo impedirem o acesso dos pacientes aos serviços de um advogado. Ao lado disso, soma-se o fato de que a própria condição social da maioria dos internos por si só já servia como obstáculo ao acesso à justiça. Respondendo às criticas de que este tipo de constrangimento feria o direito à

\footnotetext{
${ }^{42}$ CUNHA, Maria Clementina Pereira da. O espelho do mundo: Juquery a história de um asilo. Rio de Janeiro: Paz e Terra, 1986, p. 47.
} 
liberdade sendo, portanto, ilegal, Teixeira Brandão respondeu que "não pode estar constrangido em sua liberdade quem, pelo fato da moléstia, perdeu-a, não sendo mais compos sui". ${ }^{43}$ Por isso, Brandão se mostrou completamente surpreso com o fato de Ernestina ter conseguido acionar a Justiça. Para ele, esse era um "fato novo e singular". Daí pode-se imaginar a surpresa e indignação de Brandão diante da decisão do juiz Affonso de Miranda que concedeu sentença favorável à Ernestina. A sua surpresa deve ter sido amplificada pelo fato do juiz haver considerado justamente a opinião de um médico hierarquicamente inferior e, mais ainda, de uma enfermeira. Afinal, Teixeira Brandão, Cipriano de Freitas e Márcio Nery eram considerados nomes de relevo entre a comunidade médica.

Lançando mão do cabedal fornecido pela psiquiatria, Teixeira Brandão também argumentou que "todos os alienistas conhecem um grande número de doentes que não só dissimulam durante meses o delírio como, no caso de o manifestarem, fazem-no com uma lógica a levar a convicção de que afirmam aos espíritos os mais esclarecidos e prevenidos: são os que sofrem de psicose sistematizada progressiva, psicopatia de marcha lenta e de difícil cura" ${ }^{44} \mathrm{Na}$ opinião de Teixeira Brandão, reclamar da internação, dos médicos, das condições dos asilos e das atitudes dos familiares e pessoas próximas faz parte do processo de muitas doenças psiquiátricas. Segundo esta ótica, as reclamações e reivindicações dos que recebiam algum diagnóstico de alienação mental quase nunca condiziam à realidade, pois seriam geradas pela própria desorganização causada pela doença. Para efeito, tais doentes não deveriam ter suas vontades ouvidas por elementos externos, afinal: "o sintoma predominante nesta moléstia é o delírio de perseguição, ao qual, dentro em pouco tempo, depois da entrada para o asilo, o médico fica incorporado".

Na verdade, Brandão também estruturou seu discurso sobre a legitimidade da internação, realçando a imagem da periculosidade desses indivíduos. Segundo ele: "um grande número de moléstias mentais se caracteriza por intervalos de lucidez relativa, senão de completa suspensão da perturbação da inteligência entre uma fase e outra. Basta-me citar algumas, cujas designações exprimem o que deixei dito: psicoses intermitentes, periódicas, de dupla forma, circular,

\footnotetext{
${ }^{43}$ Relatório anual enviado ao ministro da Justiça, relativo ao ano de 1897. ${ }^{44}$ Ibidem, p 393.
} 
de formas alternadas etc". ${ }^{45}$ Ou seja, a condição de cidadania tutelada pelos alienistas era justificada pelo discurso técnico-científico sustentado por Teixeira Brandão, deixando bastante claro que os psiquiatras deveriam ser os únicos elos que ligariam a figura do interno alienado à sociedade. Indo além na defesa de seu ponto de vista, Brandão alertou para o suposto perigo representado pelo julgamento leigo do juiz que poderia conceder a liberdade aos indivíduos diagnosticados como loucos: "como para os doentes de tais moléstias o assassinato e todos os atentados que praticam são ditados pela necessidade da legítima defesa e de justificado desforço, muito precária será a condição do médico diante de um alienado dessa categoria a quem foi concedido o habeas corpus" ${ }^{46}$

Como pudemos notar até aqui, o relatório de 1897 foi bastante incisivo quanto aos perigos representados pelos alienados. Para Brandão, a internação é um dever do médico que se reveste do poder de autoridade pública, argumentando que este ato protegia tanto a sociedade quanto o indivíduo, "não obstante todas as garantias da liberdade individual consagradas". Além de se valer do discurso proferido pelo presidente da República, esta premissa se baseia na ideia de que "a ciência não considera louco algum inofensivo", 47 pois os doentes não podem ser responsabilizados pelos atos que possam vir a cometer.

Contudo, se na opinião de Teixeira Brandão os pacientes interditados estariam isentos de serem responsabilizados pelos atos futuros, suas inquietações dirigiam-se à responsabilidade do próprio médico. Neste sentido, ele questionou a "responsabilidade criminal dos alienistas perante a matéria". Por isso, encerrou seu relatório com um apelo dirigido ao ministro da Justiça para que o próprio interviesse junto às instâncias que competiam à regulação da matéria, argumentando que a intromissão dos juizes na decisão de libertarem os alienados era um abuso que punha em risco a sociedade e que poderia provocar problemas jurídicos aos alienistas.

Os anos subsequentes ao relatório de 1897, notadamente as três primeiras décadas do século XX, demonstram que estas ideias de Teixeira Brandão foram apropriadas e adaptadas a outros tempos e circunstâncias. Contudo, levando-se em consideração o fato de que as pesquisa empreendidas no arquivo do antigo HNA revelam que a quase totalidade dos pacientes não teve sua interdição

\footnotetext{
${ }^{45}$ Ibidem.

${ }^{46}$ Ibidem.

${ }^{47}$ Ibidem.
} 
avalizada pela Justiça, verifica-se que o preceito do exclusivo juízo alienista contabilizou muito mais vitórias que derrotas durante este período, tornando o caso Ernestina Ribeiro de Azevedo bastante singular dentro do conjunto que engloba os demais casos de internação.

\section{Conclusão}

Alguns pontos deste texto merecem destaque especial. O primeiro certamente deve se referir à figura de Ernestina Ribeiro de Azevedo. Conforme apresentado no artigo, era extremamente difícil uma pessoa internada por motivo de alienação mental ter acesso à Justiça e aos serviços de um advogado. A análise de sua condição social, (branca, rica, filha de um visconde), explica parte das condições que lhe permitiram se defender na Justiça. Afinal, o acionamento de sua rede de relações pessoais certamente foi imprescindível para que ela realizasse este intento. Por outro lado, há nos arquivos do Instituto Nise da Silveira (antigo HNA) exemplos de outros casos análogos cujos desfechos foram inteiramente favoráveis aos psiquiatras, o que torna o processo de Ernestina ainda mais singular dentro deste contexto. ${ }^{48}$ Cabe assim, analisarmos as estratégias utilizadas por Carlos Augusto de Carvalho, seu advogado, para vislumbrarmos algumas das outras razões que lhe foram favoráveis.

O advogado mostrou-se hábil em argumentar que o sistema jurídico não previa que a decisão sobre a custódia coubesse a outro poder, senão ao Judiciário. Quanto à questão sobre a sanidade de Ernestina, Carlos Carvalho se valeu da opinião de outros elementos que constituíam o universo do HNA para atestar a incongruência no diagnóstico de sua cliente. É certo que o dr. Francisco Cláudio Sá Ferreira e, menos ainda por ser enfermeira, Josephina Quirina, não tinham o mesmo relevo e credibilidade quanto Afrânio Peixoto ou Cipriano de Freitas. Porém, ao lançar mão desses depoimentos, o advogado explorou um dos pontos fracos do alienismo: as imprecisões e ambiguidades que cercavam os diagnósticos da época. Baseado nas incertezas dos médicos, o advogado abriu caminho para que o juiz especulasse sobre as intenções de Sebastião Azevedo em manter Ernestina internada.

\footnotetext{
${ }^{48}$ Exemplos destes casos foram magistralmente discutidos por: ENGEL, Magali. Ibidem. CARRARA, Sérgio. Crime e loucura: o aparecimento do manicômio judiciário na passagem do século. Rio de Janeiro: UFRJ, Museu Nacional. PPGAS, 1987.
} 
É verdade que o desfecho da causa de Ernestina pôde ter representado um forte revés para Teixeira Brandão e seus partidários, já que inaugurou um precedente jurídico que lhes era perigoso. Assim, os problemas apresentados durante o processo exigiram novas respostas por parte dos alienistas. Um dos pontos críticos refere-se à admissão dos enfermos no HNA. Apesar da opinião contrária de Teixeira Brandão e das citadas modificações nas leis que regiam a assistência médico-legal dos insanos, ficou conservada a hierarquia das leis. Tal fato manteve o Judiciário enquanto detentor do exclusivo poder de decisão sobre a custódia. Porém, a prática da pesquisa nos arquivos do antigo HNA mostrou que uma quantidade ínfima de internados conseguiu acessar o aparato judiciário e, consequentemente, ter seus direitos cumpridos. Manteve-se assim, mesmo na informalidade, a prática dos alienistas decidirem sobre a custódia médica dos insanos.

Contudo, no que tange aos métodos de peritagem, os alienistas buscaram se adaptar às possíveis situações de disputa jurídica uniformizando seu sistema de emissão de laudos, para que assim seus argumentos tivessem menos chances de serem rebatidos num tribunal. E foi neste contexto, no tribunal, que se aguçou a exigência pela adoção de procedimentos médico-legais com maior uniformidade no fundamento lógico, e cujo discurso obedecesse algumas normas mais convincentes ao olhar jurídico. Cabe atentar para o fato de que não houve uma submissão do método alienista à práxis jurídica. Afinal, as adaptações e mudanças de rumo visavam justamente o fortalecimento do alienismo enquanto autônoma esfera de atuação da medicina.

A tendência de elevação da uniformidade no emprego das técnicas de peritagem também não significou que as imprecisões nos diagnósticos tivessem sido abolidas. Pelo contrário, o advento de novas teorias tornava a exatidão diagnóstica um ponto ainda mais difícil de ser atingido. Este foi, certamente, um dos pontos frágeis da psiquiatria na Primeira República, pois foi duramente atacada tanto por juristas quanto por médicos generalistas que criticavam o modo como os psiquiatras emitiam seus laudos. O jurista Tobias Barreto, no seu livro Menores e loucos no Direito criminal, de 1884, já elaborava a seguinte crítica: "ainda hoje os alienistas e psiquiatras não estão de acordo sobre o modo exato de denominar as moléstias mentais, determinar o seu conceito e sujeitá-las a uma classificação. Cada autor apresenta a sua maneira de ver, que pode ser mais ou menos aceitável, mas não é definitiva. No emprego mesmo das palavras domina a maior diversidade". Anos mais tarde, este mesmo trecho da obra de Tobias 
Barreto foi citado por Souza Lima, jurista autor do Tratado de Medicina legal, cuja primeira edição data de 1905. Em 1936, foi lançada sua sexta edição desta obra de fôlego que manteve a citação de Tobias Barreto, bem como as críticas à permanência da imprecisão dos diagnósticos psiquiátricos, salientando as injustiças e arbitrariedades que este problema causava.

\section{Anexo I}

\section{I - Preliminares:}

Menção da autoridade que ordenou o exame; fins e condições deste; quesitos judiciais; material de observação (processo, informações, exames diretos etc.).

\section{II - História do caso:}

Nome, cidade, raça, profisssão, estado civil, religião, naturalidade do examinado.

1 - Anamnese:

A) Balanço genealógico: estado de saúde da família; doenças nervosas e mentais; alcoolismo; sífilis; particularidades estranhas; crimes; suicídios; consanguinidades; casamentos desproporcionados em idade; acidentes da prenhez materna respectiva; parto laborioso; operado; nascimento legítimo ou espúrio.

B) Infância: estados nevropáticos; convulsões; doenças febris, eruptivas e outras; intoxicações; início e condições da marcha e da palavra; dentição; desenvolvimento do físico, da inteligência e do caráter; alterações da evolução normal, perversão dos sentimentos, por traumatismo, doença, causas diversas; conduta no meio doméstico e na escola; educação em colégio, asilo, convento; desenvolvimento sexual, onanismo precoce; hábitos anormais; raivas estateladoras, mentiras caluniosas, furtos, assombramentos, terrores noturnos, pesadelos, loquacidade hipnológica; micção no leito.

C) Puberdade: parada de desenvolvimento mental; perturbações psíquicas transitórias; convulsões; risos, choros imotivados; primeira menstruação, regra catamenial; primeiras práticas sexuais; masturbação; ergastenia por estafa mental, cansaço físico ou esgoto venéreo.

D) Idade adulta: caráter, regularidade, firmeza; inclinações: etilismo, jogo, libertinagem, usura, vaidade, filantropia, coleções etc.; instalação na vida, protegido ou desabrigado; particularidades nos costumes, hábitos, gostos; casamento, relações com o outro cônjuge, lar feliz ou desacorde, quantos filhos vivos, condições de sua sobrevivência, quantos mortos, causa letal especificada, prenhez a termo e abortadas, seus intervalos, menopausa próxima ou chegada; condições de vida, trabalho, preocupações de fortuna e bem-estar social; doenças infecciosas graves, sífilis, febres eruptivas, tífica, amarela, peste, pneumonia, gripe etc.; intoxicações agudas ou crônicas pelo álcool, tabaco, chumbo, arsênio, alimentos deteriorados etc.; traumatismos físicos e psíquicos, quedas, emoções violentas; doenças nervosas e mentais antecedentes, forma, caráter, evolução, duração, tratamento das mesmas; acusações e condenações anteriores; excessos, privações, perversões genésicas; operações cirúrgicas pregressas; atos e crimes atribuídos, informados pelo processo, depostos pelo examinado. 


\section{2 - Exame direto}

A) Atitudes, apresentação, musculatura (atrofias), desproporções (aleijados, anões), adiposidade, cor da pele e das mucosas, pelugem; vícios de conformação (pé chato, poli e hipodactilia; assimetrias: orelhas em asa, em ponta, beiço de lebre, goela de lobo etc.).

B) Cabeça, forma, deformações, assimetrias; diâmetros transverso e longitudinal máximos, curva transversa biauricular; índice cefálico; calvície; sensibilidade à pressão; percussão.

C) Face, desvios, contração, tremores, sensibilidade dos pontos nervosos à pressão; cicatrizes. Olhos, tempo visual, vícios de refração, estrabismo, daltonismo, desigualdade cromática das íris, desigualdade pupilar, exame oftalmoscópio, se preciso. Língua e boca: projeção, tremores grossos ou fibrilares, saburra; dentes, excessivos, vícios de implantação, abóbada palatina, estreita, funda, em carena. Nariz, formas, desvios do septo.

D) Órgãos torácicos e pubianos; inversões viscerais; desvios, deformações; hérnias; pulso; ritmo respiratório e cardíaco.

E) Sensibilidade: tátil, térmica, dolorosa. Sentido muscular. Sinal de Romberg. Zonas histerógenas.

F) Motilidade: dinamometria, paralisias, paresias, contraturas, convulsões, tremores, temor intencional, incoordenação, tremor da mão estendida, tetania, catalepsia.

G) Reflexos: pupilar, faríngeo, rotuliano, abdominal, plantar, aquiliano etc.

H) Exame de urina, reação, toxidez, fosfatos, açúcar, albumina.

I) Fala: voz baixa ou forte. Fala tranquila, demorada, arrastada, rápida, fluente, taciturna, ascendente, tremulante, tropeçante, incoordenada, afonia, mutismo. Repetição dos paradigmas (libélula, flanela leve, três mil trezentos e trinta e três artilheiros da terceira brigada de artilharia). Contrações correlatas dos músculos da face, lábios etc.

J) Escrita: mediante ditado, usando paradigmas, ou espontânea, em cartas, memoriais, composições literárias, publicações, testamentos, desenhos etc., apreciando intensidade, forma, dimensão, direção, continuidade, ordem, simplificado.

\section{3 - Exame mental}

A) Noção de tempo, lugar e meio.

B) Confusão do espírito, alheamento ao mundo exterior.

C) Humor do examinado, com ou sem correspondência no meio ambiente: alegre, arrogante, folgazão, reservado, desconfiado, triste, amoroso, indiferente, colérico, furioso. Explicação deste estado pelo arguido. Excitação, depressão, angústia. Associação de ideias, tarda ou precipitada: logorréia, silabação, apatia ou delírio de ação. Atos extravagantes, ridículos, pueris, desonestos, imundos, violentos, agressivos, destruidores, estereotipados, miméticos, sem causalidade nem efeito, saltos, danças, corridas etc., transformações da personalidade.

D) Percepção, ilusões, alucinações, delírios: de perseguição, grandeza, ruína, pecado, negação, querela, possessão demoníaca, divina etc.; fixos, imutáveis, coerentes, raciocinados, organizados em sistemas ou transitório, fugazes; variados, desconexos, insustentáveis. Relações ao meio; impulsões.

E) Inteligência: precipitação, volubilidade, incoordenação das ideias. Correspondência entre ideias atuais e a educação recebida: desintegração das aquisições da cultura, cálculo, religião, história, política, geografia. Memória: fatos antigos e recentes. Juízo do examinado sobre si mesmo e sobre os outros.

F) Estado geral da nutrição. Sono, insônias, autointoxicações. 


\section{III - Somatório}

$1^{\circ}$ - Súmula das aquisições que denunciam doença.

$2^{\circ}$ - Juízo sobre alienação existente ou não, na fase de exames; prejulgamento, se possível, do estado no momento do crime ou outra ação importante à Justiça ou causa pública.

$3^{\circ}$ - Dedução diagnóstica, caracterizando a forma nosológica, se possível.

$4^{\circ}-$ Resposta aos quesitos propostos.

\section{Referências bibliográficas}

ABBOTT, Andrew. The system of professions: an essay on the division of expert labor. University of Chicago Press.

BERCHERIE, Paul. Os fundamentos da clínica: história e estrutura do saber psiquiátrico. Rio de Janeiro: Jorge Zahar Editor, 1989.

BIRMAN, Joel. A psiquiatria como discurso da moralidade. Rio de Janeiro: Graal, 1978.

CARRARA, Sérgio. O crime de um certo Custódio e o surgimento do manicômio judiciário no Brasil. Dados - Revista de Ciências Sociais. Rio de Janeiro, vol. 34, no 2, 1991, p. 279-301.

CASTEL, Robert. A ordem psiquiátrica: a idade de ouro do alienismo. Rio de Janeiro: Edições Graal, 1978.

COSTA, Jurandir. Ordem médica e controle familiar. $3^{\mathrm{a}} \mathrm{ed}$. Graal.

COSTA, Jurandir. História da psiquiatria no Brasil: um corte ideológico. Rio de Janeiro: Xenon ed.

CUNHA, Maria Clementina Pereira da. O espelho do mundo: Juquery a história de um asilo. Rio de Janeiro: Paz e Terra, 1986.

CUNHA, Maria Clementina Pereira da. De historiadoras, brasileiras e escandinavas: loucuras, folias e relações de gêneros no Brasil (século XIX e início do XX). Tempo. Rio de Janeiro. vol. 3, nº 5, 1998, p. 181-215.

CUNHA, Maria Clementina Pereira da. Loucura, gênero feminino: As mulheres do Juquery na São Paulo do início do século XX. Revista Brasileira de História. São Paulo. v. 9, nº 8, p. 121-144.

DESVIAT, Manuel. A reforma psiquiátrica. Rio de Janeiro: Editora Fiocruz, 1999.

DI LISCIA, Maria. Médicos, jueces y locos. Sobre peritaje de insania y justicia en el interior argentino, 1890-1930. 
ENGEL, Magali Gouveia. Os delírios da razão: médicos, loucos e hospícios (Rio de Janeiro 1830-1930). Rio de Janeiro: Editora Fiocruz, 2001.

ENGEL, Magali Gouveia. Meretrizes e doutores: saber médico e prostituição no Rio de Janeiro. São Paulo: Brasiliense, 1989.

ENGEL, Magali Gouveia. Psiquiatria e feminilidade. In: DEL PRIORI, Mary (org.). História das mulheres no Brasil. São Paulo: Unesp, 2001.

FOUCAULT, Michel. História da loucura. Editora Perspectiva: São Paulo, 1996.

FOUCAULT, Michel O nascimento da clínica. Rio de Janeiro: Forense Universitária, 1994.

FOUCAULT, Michel. Em defesa da sociedade. São Paulo: Martins Fontes, 1999.

FRAYZE-PEREIRA, João A. O que é loucura. São Paulo: Editora Brasiliense, 1982.

FRY, Peter \& CARRARA, Sérgio. As vicissitudes do liberalismo no Direito penal brasileiro.

HARRIS, Ruth. Assassinato e loucura: medicina, leis e sociedade no fin de siécle. Rio de Janeiro: Rocco, 1993.

PESSOTTI, Isaias. A loucura e as épocas. Rio de Janeiro: Editora Nova Fronteira, 1994.

PESSOTTI, Isaias. O século dos manicômios. $1^{\mathrm{a}}$ reimpressão. São Paulo: Editora 34, 2001.

SKALEVAG, Svein Atle. The matter of forensic psychiatry: a historical enquire. In: Medical history, 2006. 